\title{
Fundamental Frequency Modulated Multilevel Inverter for Three-Phase Stand-Alone Photovoltaic Application
}

\author{
E. Ozdemir ${ }^{1}$, S. Ozdemir ${ }^{1}$, L. M. Tolbert ${ }^{2,3}$, B. Ozpineci ${ }^{3}$ \\ ${ }^{1}$ Kocaeli University, Faculty of Technical Education, Department of Electrical Education, Umuttepe, Kocaeli, 41380, Turkey \\ 2 The University of Tennessee, Electrical Engineering and Computer Science, 311 Ferris Hall, Knoxville, TN 37996-2100, USA \\ ${ }^{3}$ Oak Ridge National Laboratory, Power Electronics and Electric Machinery Research Center, Knoxville, TN 37831-6472, USA
}

\begin{abstract}
This paper presents a fundamental frequency modulated multilevel inverter scheme for use with a three-phase stand-alone photovoltaic (PV) system. The system consists of four series connected PV arrays, a five-level diode-clamped multilevel inverter (DCMLI) generating fundamental modulation staircase three-phase output voltages, and a three-phase induction motor as the load. In order to validate the proposed concept, simulation studies and experimental measurements, done using a small-scale laboratory prototype, are also presented. The results show the feasibility of the fundamental switching application in threephase stand-alone $P V$ power systems.
\end{abstract}

\section{INTRODUCTION}

Solar energy is one of the favorable renewable energy resources, and the multilevel inverter has been proven to be one of the important enabling technologies in PV utilization. Multilevel voltage source inverters offer several advantages compared to their conventional counterparts. By synthesizing the ac output terminal voltage from several levels of voltages, staircase waveforms can be produced, which approach the sinusoidal waveform with low harmonic distortion; thus, reducing filter requirements. The need of several sources on the dc side of the converter makes multilevel technology attractive for photovoltaic applications [1].

There are numerous PV power systems ranging from $100 \mathrm{~W}$ to several megawatts [2]. As the PV cells generate dc power, a power conditioning system is also required, in order to suit the frequency and voltage level to the load required and allow the parallel connection. In addition, a PV system must present some features related to the safety, efficiency, and power quality. Several configurations of PV power conditioning systems, employing various static converter topologies, can be found in technical literature [3-5].

The problem of eliminating harmonics in switching inverters has been the focus of research for many years. The current trend of modulation control for multilevel inverters is to output high quality power with high efficiency. For this reason, popular traditional PWM modulation methods are not the best solution for multilevel inverter control due to their high switching frequency. The selective harmonic elimination method has emerged as a promising modulation control method for multilevel inverters. The major difficulty for the selective harmonic elimination method is to solve the equations characterizing harmonics; however, the solutions are not available for the whole modulation index range. The proposed method is used to eliminate any number of harmonics and can be applied to DCMLI application requirements.

In this paper, a five-level DCMLI fundamental frequency switching strategy is proposed by selecting the switching angles such that the lower order harmonics are eliminated. In this study, a harmonic elimination technique is presented that allows one to control a multilevel inverter in such a way that it is an efficient low total harmonic distortion (THD) inverter that can be used to interface distributed dc energy sources with a main ac grid or as an interface to a motor drive powered by fuel cells, batteries, or ultra-capacitors. A prototype was built to verify the operation of the proposed topology, and it presented good performance in terms of efficiency and power quality.

\section{DiOde-Clamped MUltileVEL INVERTER}

Fig. 1 shows the proposed three-phase stand-alone PV power system configuration. The five-level DCMLI powered by four PV arrays drives a three-phase induction motor. Four series PV arrays connected on the dc bus of a three-phase fivelevel diode-clamped multilevel inverter topology are shown in Fig. 2. Controlling the switches can generate the five-level output voltage. The complementary switch pairs for phase leg $a$ are $\left(S_{a 1}, S_{a^{\prime} 1}\right),\left(S_{a 2}, S_{a^{\prime} 2}\right),\left(S_{a 3}, S_{a^{\prime} 3}\right)$, and $\left(S_{a 4}, S_{a^{\prime} 4}\right)$. When $S_{a 1}$ is on $\left(S_{a l}=1\right), S_{a^{\prime} l}$ is off $\left(S_{a^{\prime} l}=0\right)$. Other switch pairs are similar.

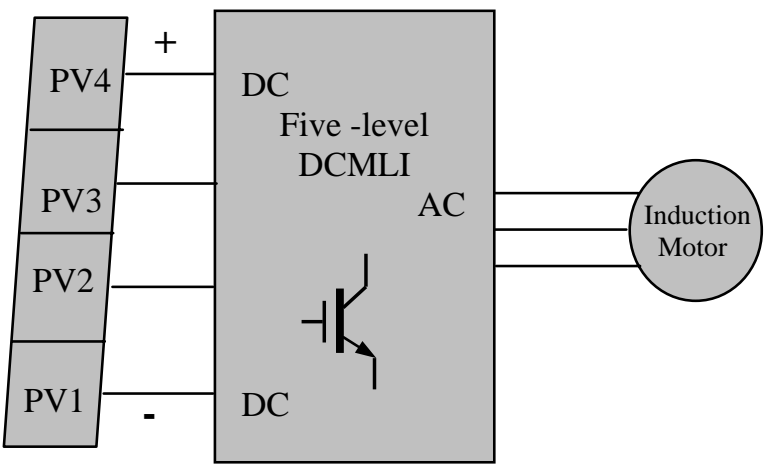

Fig. 1. The DCMLI block diagram for a stand alone PV power system configuration. 


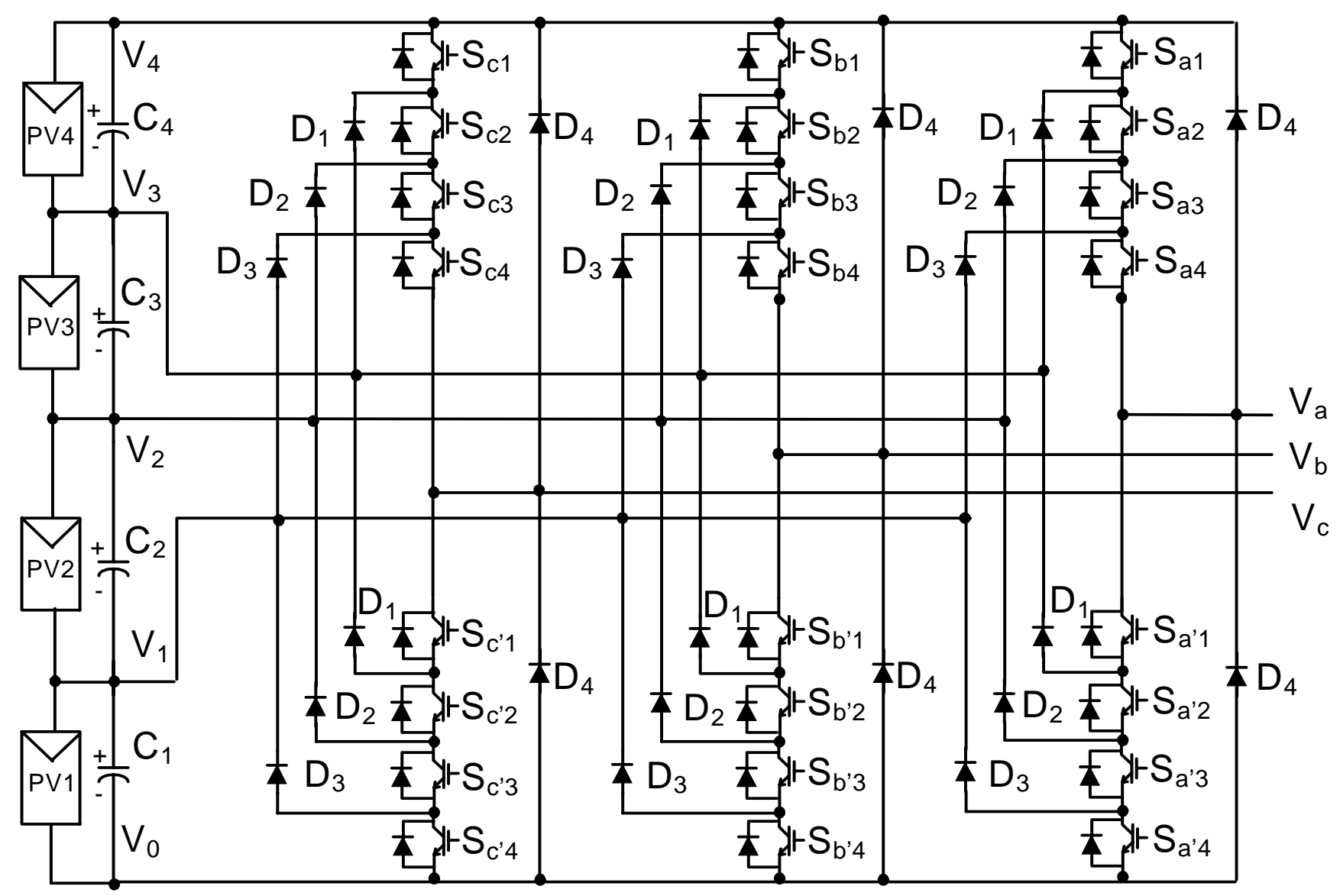

Fig. 2. PVs connected to a three-phase five-level diode-clamped multilevel inverter topology.

Fig. 3 shows one of the three-phase line voltage waveforms for a five-level DCMLI. The line voltage $V_{a b}$ consists of a phase-leg $a$ voltage and a phase-leg $b$ voltage. The resulting line voltage is a nine-level staircase waveform. This means that an $m$-level diode-clamped inverter has an $m$-level output phase voltage and a $(2 m-1)$ level output line voltage [6]. Table I lists the output voltage levels possible for one phase of the inverter with the negative dc rail voltage $V_{0}$ as a reference. State condition 1 means the switch is on, and 0 means the switch is off. Each phase has five complementary switch pairs such that turning on one of the switches of the pair require that the other complementary switch be turned off.

TABLE I

DCMLI OUTPUT Voltage LEVELS AND SWITCHING STATES

\begin{tabular}{|l|c|c|c|c|c|c|c|c|}
\hline \multirow{2}{*}{$\begin{array}{c}\text { Voltage } \\
V_{a 0}\end{array}$} & \multicolumn{7}{|c|}{ Switch State } \\
\cline { 2 - 10 } & $S_{a 1}$ & $S_{a 2}$ & $S_{a 3}$ & $S_{a 4}$ & $S_{a^{\prime} 1}$ & $S_{a^{\prime} 2}$ & $S_{a^{\prime} 3}$ & $S_{a^{\prime} 4}$ \\
\hline$V_{4}=4 V d c$ & 1 & 1 & 1 & 1 & 0 & 0 & 0 & 0 \\
\hline$V_{3}=3 V d c$ & 0 & 1 & 1 & 1 & 1 & 0 & 0 & 0 \\
\hline$V_{2}=2 V d c$ & 0 & 0 & 1 & 1 & 1 & 1 & 0 & 0 \\
\hline$V_{l}=V d c$ & 0 & 0 & 0 & 1 & 1 & 1 & 1 & 0 \\
\hline$V_{0}=0$ & 0 & 0 & 0 & 0 & 1 & 1 & 1 & 1 \\
\hline
\end{tabular}

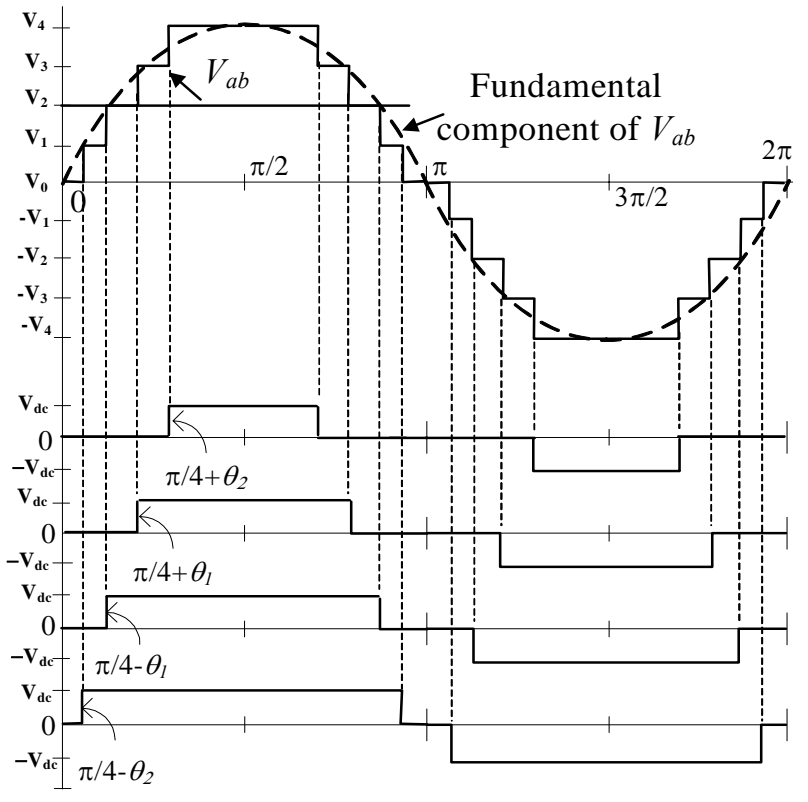

Fig. 3. Line voltage waveform for a five-level DCMLI. 
Multilevel inverters can synthesize higher voltages using devices of lower voltage rating. The wave shape and hence the $T H D$ of the output voltage improves as the number of levels increases. Multilevel inverters can be used as an alternative configuration for the conventional dc to ac inverter in photovoltaic applications. Diode clamp inverter, cascaded $\mathrm{H}$-bridge inverter and flying capacitor type inverter are the three widely used configurations of multilevel inverters. Diode clamped multilevel inverter power circuit uses the least number of DC power sources among these three configurations. Also, the diode-clamped multilevel inverter is ideally suited for systems such as photovoltaic where several level of input dc sources are available

\section{Proposed Method For Five-LeVel DCMLI}

Two important issues in multilevel inverter control are obtaining near sinusoidal output voltage waveform and the elimination of the lower order harmonics. A key concern in the fundamental switching scheme is to determine the switching angles in order to produce the fundamental voltage and not generate specific higher order harmonics. Often iterative techniques are used to calculate the switching angles [7], though such an approach does not guarantee finding all the possible solutions. Some other fundamental modulation techniques were presented in [8-10]. Previous work in [11] has shown that the transcendental equations characterizing the harmonic content can be converted into polynomial equations, which are then solved using the method of resultants from elimination theory. The work presented here is based on the previous work in [12] which concerned a cascaded H-bridges converter. However in this paper, the proposed calculation method results are used for switching of the PV supplied DCMLI.

As shown in Fig. 2, a multilevel inverter can produce a quarter-wave symmetric voltage waveform synthesized by several DC voltages. By applying Fourier series analysis, the output voltage can be expressed as

$$
\begin{aligned}
& V(t)=\sum_{n=1,3,5 \ldots}^{\infty} \frac{4 V_{D C}}{n \pi}\left(\cos \left(n \theta_{1}\right)+\cos \left(n \theta_{2}\right)+\ldots .\right. \\
& \left.+\cos \left(n \theta_{s}\right)\right) \sin (n \omega t)
\end{aligned}
$$

where $s$ is the number of dc sources, and $V_{\mathrm{DC}}$ is the level of each dc voltage. The switching angles must satisfy the condition $0<\theta_{1}<\theta_{2}<\ldots<\theta_{s}<\pi / 2$. In order to minimize the harmonic distortion and to achieve adjustable amplitude of the fundamental component, up to $(s-1)$ th order harmonics can be removed from the voltage waveform. In general, the most significant low-frequency harmonics are chosen for elimination by properly selecting angles among different level inverters, and high-frequency harmonic components can be readily removed by using additional filter circuits. To keep the number of eliminated harmonics at a constant level, all switching angles must satisfy the condition $0<\theta_{1}<\theta_{2}<\ldots<$ $\theta_{s}<\pi / 2$, or the THD level increases dramatically. Considering the symmetry of the waveform, only two switching angles need to be determined in this strategy, which are $\theta_{1}$ and $\theta_{2}$ shown in Fig. 2. For a five-level multilevel inverter, the harmonic equations are given below.

$$
\begin{aligned}
& \cos \left(\theta_{1}\right)+\cos \left(\theta_{2}\right)=m \\
& \cos \left(5 \theta_{1}\right)+\cos \left(5 \theta_{2}\right)=0
\end{aligned}
$$

where modulation index is $m=\pi V_{1} /\left(4 V_{\mathrm{DC}}\right)$. The polynomial equations are:

$$
\begin{aligned}
& p_{1}\left(x_{1}, x_{2}\right)=\sum_{n=1}^{2} x_{n}-m=0 \\
& p_{5}\left(x_{1}, x_{2}\right)=\sum_{n=1}^{2}\left(5 x_{n}-20 x_{n}^{3}+16 x_{n}^{5}\right)=0
\end{aligned}
$$

The above equations are solved and modulation index versus switching angles ( $\theta_{1}$ and $\theta_{2}$ ) calculated. Therefore, the lowest THD solution can be used for practical application for the best control performance.

\section{SimUlATION RESULTS}

Matlab/Simulink and PSIM software packages are linked to run concurrently to perform the simulation implementation by using the SimCoupler module. Blocks in Matlab/Simulink generate the proposed fundamental switching pattern. SimCoupler module is an add-on module to the PSIM software and provides an interface between Matlab/Simulink and PSIM software packages for co-simulation [13]. Fivelevel DCMLI circuit block diagram in PSIM is shown in Fig. 4. The three-phase line voltage waveforms and harmonic spectrum of the output voltage that reveal elimination of the fifth harmonic are shown in Figs. 5 and 6, respectively, for a five-level DCMLI with $24 \mathrm{Vdc}$ for each level. In order to understand phase leg and line voltage relation, phase leg voltages $\left(V_{a 0}, V_{b 0}\right)$ with respect to the negative rail and the resulting line-line voltage $\left(V_{a b}\right)$ waveforms are given in Fig. 7.

Five-level DCMLI circuit

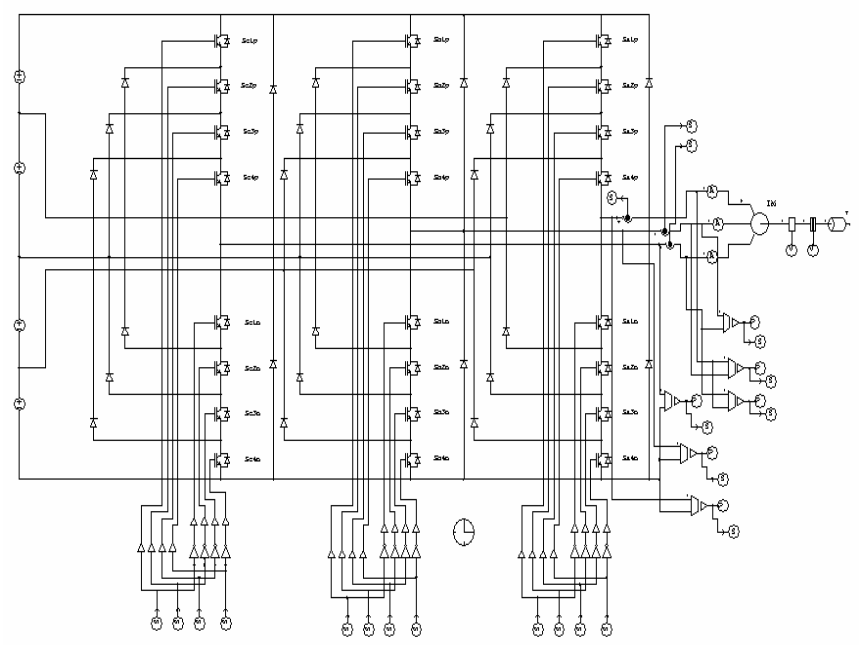

Fig. 4. Five-level DCMLI circuit block diagram in PSIM. 


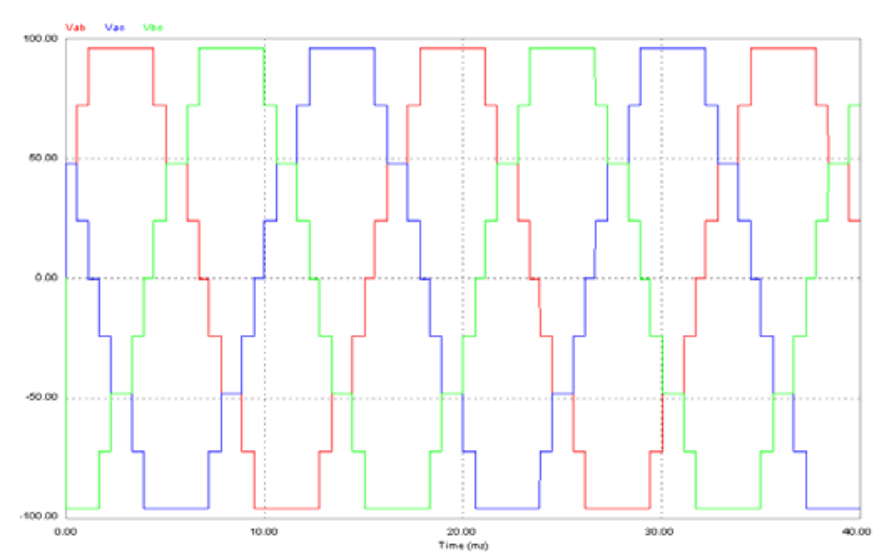

Fig. 5. Simulated DCMLI output line-line voltage waveform.

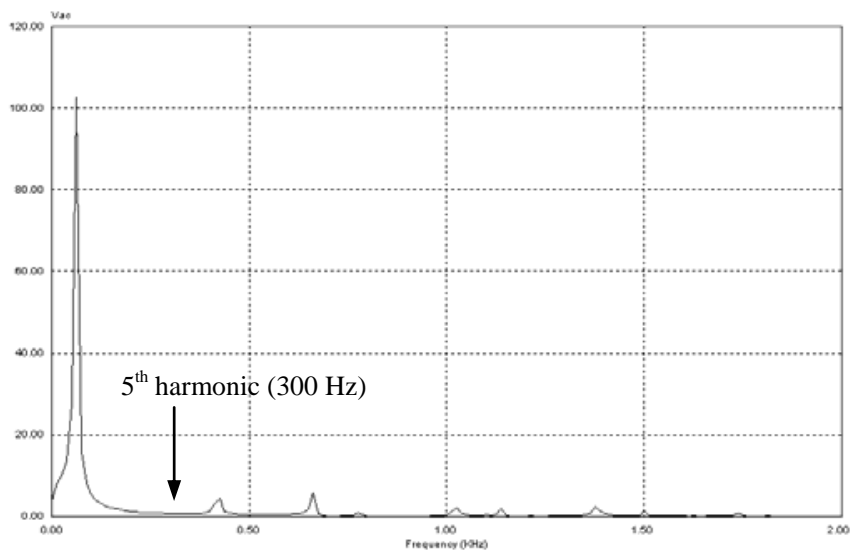

Fig. 6. Harmonic spectrum of the five-level DCMLI line voltage, $V_{a b}$ shown in Fig. 5.

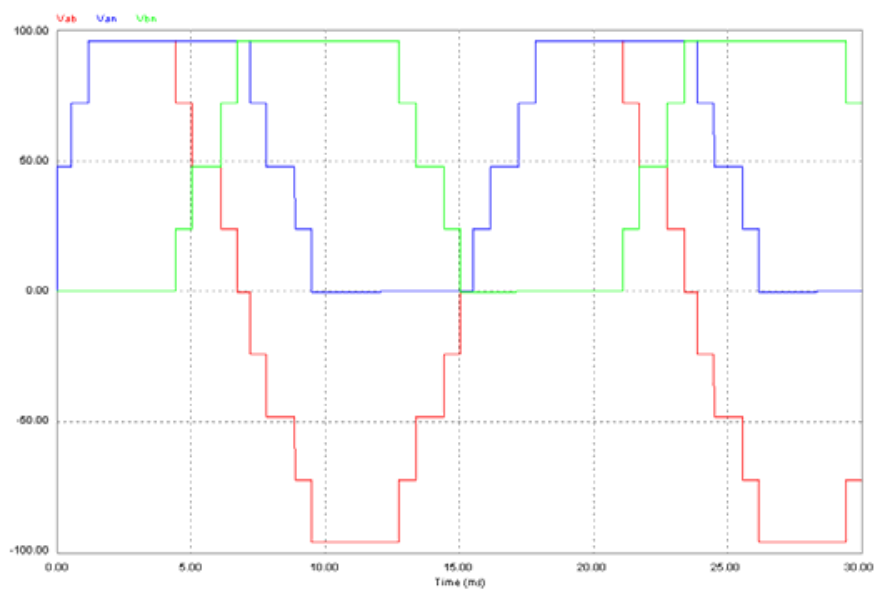

Fig. 7. Line and phase leg voltage waveforms for DCMLI.

\section{EXPERIMENTAL RESULTS}

In order to experimentally validate the proposed fundamental frequency modulation technique, four series connected PV modules (total $160 \mathrm{~W}$ ) were connected to the dc bus of a three-phase five-level DCMLI that used MOSFETs as the switching devices [16]. The DCMLI output provides power to a $250 \mathrm{~W}$ induction motor.
A picture of the laboratory experimental prototype, built to verify the operation and efficiency of the proposed method, is represented in Fig. 8 that includes PV module connections, five-level DCMLI circuit, and measurement equipment. Fig. 9 shows the photograph of the PV modules arrangement that supplies power to the multilevel inverter. Each PV module has a rated power of $10 \mathrm{~W}$ with voltage variation of 16 to $21 \mathrm{~V}$ (nominal $18 \mathrm{~V}$ ) depending on the operating conditions such as insolation, temperature, etc. Two PV modules are connected in series and two of them in parallel in order to form one PV array and to get a nominal voltage of 36 volts and $40 \mathrm{~W}$ power for each dc level (PV array) of the multilevel inverter. There are four identical PV arrays (PV1 to PV4) in the proposed photovoltaic power supply system with an installed power generating capacity of $160 \mathrm{~W}$ from a total of $16 \mathrm{PV}$ panels. The PV panels are mounted outside such that the panels receive maximum solar energy during most of the day.

A total of $160-\mathrm{W}$ peak power PV module power source and a five-level multilevel inverter have been developed in laboratory. Specifications of the main components of the PV power system in laboratory are shown in Table II. It is important to comment that all components of the five-level DCMLI are oversized due to the laboratory component availability. The DCMLI switching frequency has been chosen as fundamental in order to achieve low switching losses.

In this work, the RT-LAB real-time computing platform from Opal-RT-Technologies Inc. [14] was used to interface the computer (which generates the logic signals) to the fivelevel DCMLI. The Opal RT-Lab system is utilized to generate gate drive signals and interfaces with the gate drive board. This system allows one to implement the switching algorithm in Simulink which is then converted to $C$ code using RTW (real-time workshop) from Mathworks. The RT-LAB software provides icons to interface the Simulink model to the digital I/O board and converts the $C$ code into executables. The step size for the real-time implementation was 10 microseconds. This small step was used to obtain an accurate resolution for implementing the switching times.

The conversion efficiency of the inverter, which was measured with a Yokogawa PZ 4000 power analyzer, at low power levels is more than 95\%, and the maximum efficiency is about $98.5 \%$, which is comparatively higher than conventional inverters. Negligible switching losses occur for this system due to the low switching frequency employed. In the present case, the main causes of inverter losses are related to semiconductor conduction losses. Each switch in the inverter switches only once per cycle when performing fundamental frequency switching; this results in high efficiency.

TABLE II

SPECIFICATIONS OF THE PV POWER SYSTEM IN LABORATORY

\begin{tabular}{|l|l|l|l|}
\hline \multicolumn{2}{|c|}{ PV Modules Shell ST10 } & \multicolumn{2}{c|}{ DCMLI } \\
\hline $\begin{array}{l}\text { Rated power of each PV } \\
\text { module }\end{array}$ & $10 \mathrm{~W}$ & \# of levels & 5 level \\
\hline Open circuit voltage & $22.9 \mathrm{~V}$ & Number of DC sources & 4 \\
\hline Short circuit current & $0.77 \mathrm{~A}$ & Line voltage (ACrms) & $70 \mathrm{~V}$ \\
\hline $\begin{array}{l}\text { Rated power of PV } \\
\text { system }\end{array}$ & $160 \mathrm{~W}$ & DC link voltage & $\begin{array}{l}144 \mathrm{~V} \\
4 \times 36 \mathrm{~V}\end{array}$ \\
\hline
\end{tabular}




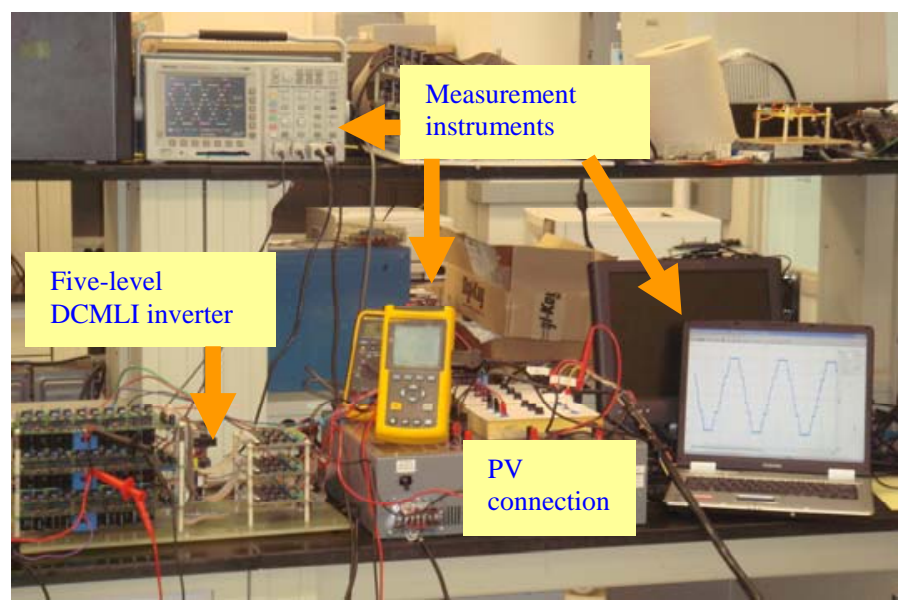

Fig. 8. The six-level DCMLI experimental setup.

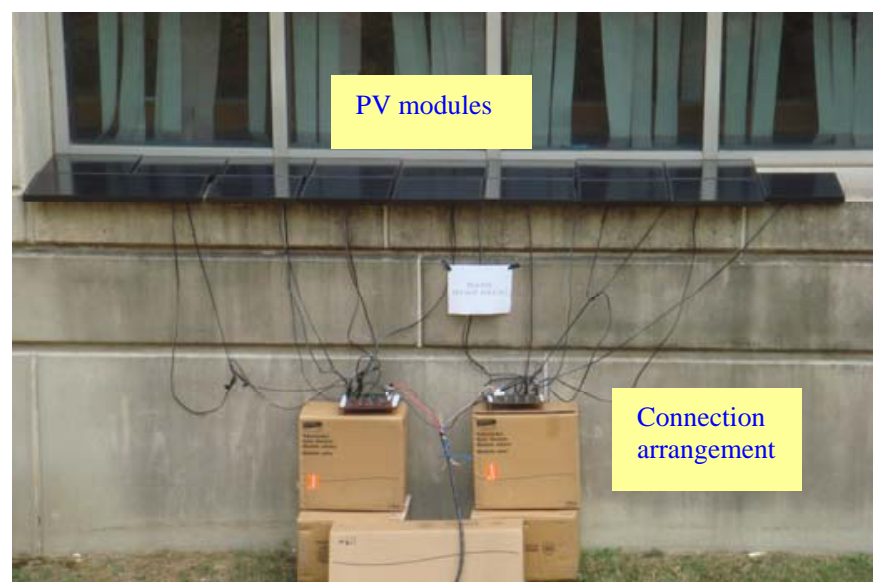

Fig. 9. The photograph of PV arrangement comprised of 16 PV modules.

Fig. 10 shows the experimental three-phase phase line voltages and output current waveform. The THD of the lineline voltage was computed using the data in Fig. 11 and was found to be $9.2 \%$. Its corresponding Fast Fourier Transform (FFT) spectrum shows that the $5^{\text {th }}, 13^{\text {th }}$ and triplen harmonics are absent from the waveform. Experimental verification that the low order harmonics are indeed eliminated is also presented by driving a three- phase induction motor from a five-level DCMLI. Since five-level DCMLI can generate a nine-level line-to-line staircase waveform, the generated voltage and current waveforms are sinusoidal shape even at fundamental switching frequency. Fig. 12 shows experimental line voltage and load current waveforms together.

High efficiency converters are desirable for renewable energy systems, especially those related with photovoltaic applications. In this paper, a fundamental frequency switching analysis for the five-level DCMLI is presented. This circuit minimizes the number of switches per level and has the same advantages of other multilevel circuits but keeps the conduction losses at acceptable levels. Low switching frequency operation is also investigated and simulation and experimental results given.

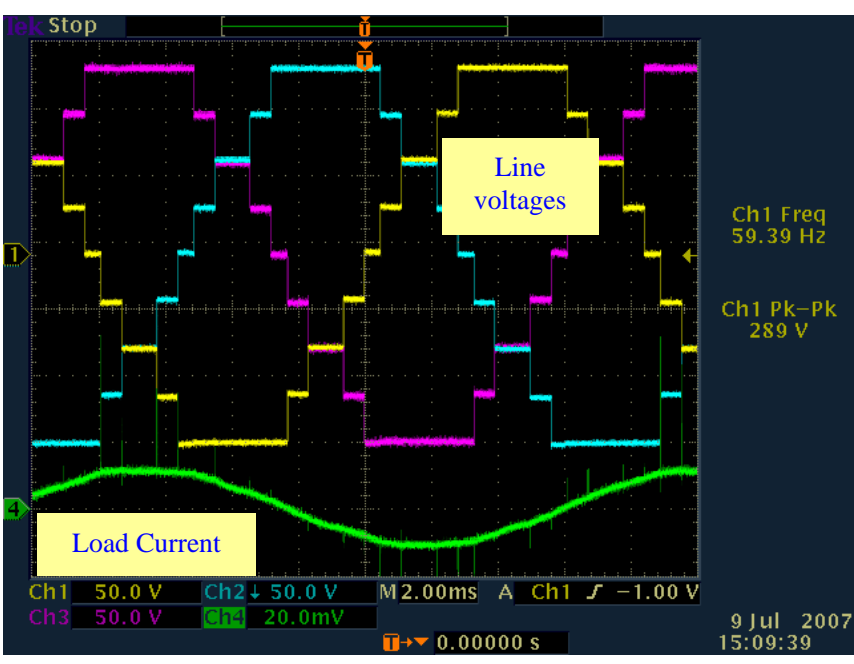

Fig. 10. Experimental three-phase line voltages and load current waveforms.

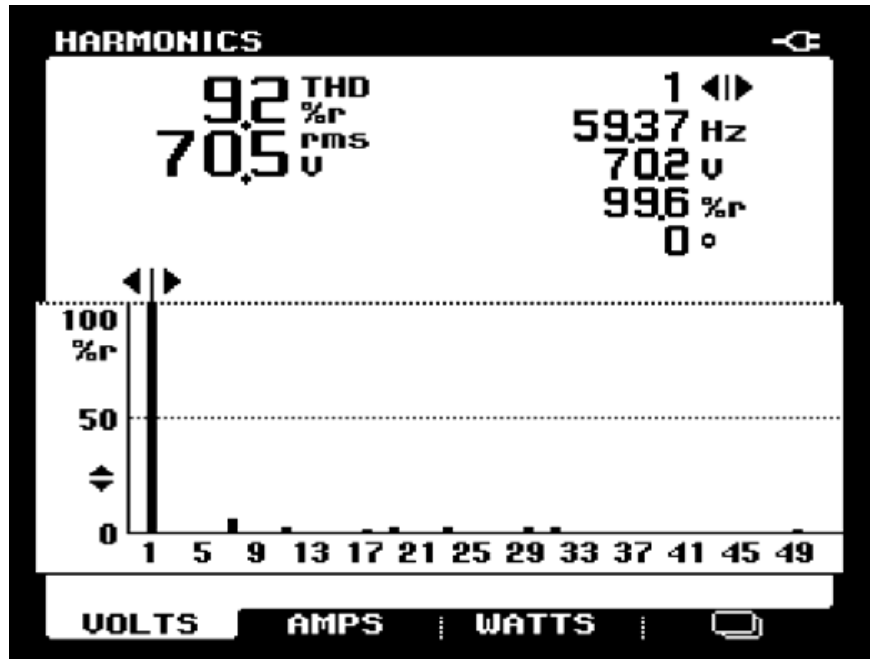

Fig. 11. FFT spectrum of five-level DCMLI experimental output line voltage.

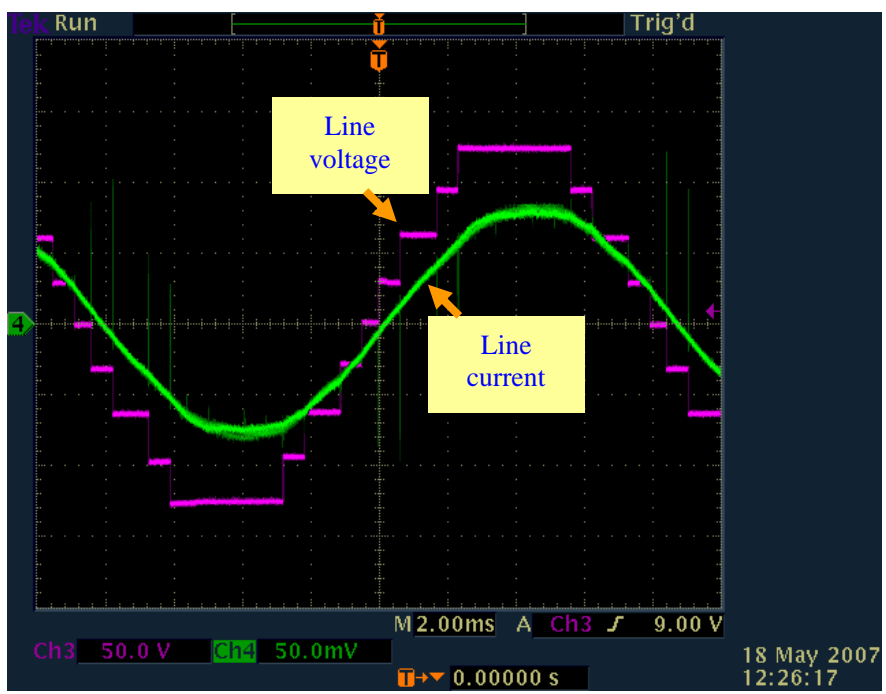

Fig. 12. Experimental line voltage and current waveforms. 
The validity of the proposed stand-alone PV system is verified through computer-aided simulations and experimental results using a five-level diode-clamped multilevel converter prototype. The results show the feasibility of the application of this new fundamental switching application on three-phase PV power systems.

Although the developed PV-based power generation system belongs to a stand-alone power generation approach, maximum-power-point-tracking and modified multilevel inverter control algorithms can be applied to form a gridconnected generation framework in the future.

\section{CONCLUSION}

This study has successfully developed a new fundamental frequency switching scheme for a three-phase stand-alone PV generation system. The effectiveness of the five-level diodeclamped multilevel inverter control scheme for the three-phase stand-alone PV generation system was verified by realistic experimentations. According to the experimental results, the maximum conversion efficiency of the multilevel inverter is about $98.5 \%$, which is comparatively higher than conventional high frequency PWM-based inverters. Moreover, the ac output voltage of the multilevel inverter is a near-sinusoidal waveform, and the corresponding THD values of load current under different loads are generally less than 5\%, which satisfies the harmonic standards for most applications.

The proposed five-level diode-clamped multilevel inverter has several promising advantages for the use of a three-phase stand-alone photovoltaic system. First, it can convert power from several relatively low dc voltage sources to a higher ac voltage by itself (without transformers or high frequency switching). Second, it increases output voltage levels without any transformer that reduce the losses and weight of the overall system. Third, in case of a five-level multilevel inverter operating as a motor drive, it does not require an output filter because high-order harmonics are effectively filtered off, owing to the reactance of the induction motor load; therefore, it can produce a high quality output voltage wave with a good harmonic characteristic. Finally, it reduces stresses on power switching devices, resulting in low audio and radio frequency (RF) noise and electromagnetic interference (EMI), and fewer electromagnetic compatibility (EMC) problems, since multilevel inverter operates with a low switching frequency and voltage switching is done for relatively lower voltage levels.

Although the developed PV-based power generation system belongs to a stand-alone power generation approach, maximum-power-point-tracking and modified the fundamental frequency switching algorithms can be applied to form a gridconnected generation framework. The application presented in this paper is applicable to rural areas where there is no grid connection to the utility network.

\section{ACKNOWLEDGMENT}

In this study, Dr. Engin Ozdemir was supported by TUBITAK postdoctoral research fund R-2219 for his studies in The University of Tennessee in USA.

\section{REFERENCES}

[1] M. Calais. V. G. Agelidis, "Multilevel converters for single-phase grid connected photovoltaic systems - An overview," Proc. ISIE'98, vol. 1, 1998, pp. 224-229.

[2] B. Kroposki, R. de Blasio, "Technologies for the new millennium: Photovoltaics as a distributed resource,” Proc. IEEE Power Eng. Soc. Summer Meeting, 2000, pp. 1798-1801.

[3] P. G. Barbosa, H. A. C. Braga, Md. C. B. Rodrigues, E. C. Teixeira, "Boost current multilevel inverter and its application on single-phase grid-connected photovoltaic systems;” IEEE Trans. on Power Electronics, vol. 21, no. 4, July 2006, pp. 1116 - 1124.

[4] H. Valderrama-Blavi, M. Munoz-Ramirez, J. Maixe, R. Giral, J. Calvente, "Low frequency multilevel inverters for renewable energy systems" Proceedings of the IEEE International Symposium on Industrial Electronics, vol. 3, 20-23 June 2005, pp. 1019 - 1024.

[5] R. L. Naik, K. R. Y. Udaya, “A novel technique for control of cascaded multilevel inverter for photovoltaic power supplies” European Conference on Power Electronics and Applications, 11-14 Sept. 20059 pages.

[6] S. Khomfoi, L. M. Tolbert, "Multilevel power converters - Chapter 17," Power Electronics Handbook, 2nd Edition, Elsevier, 2007, ISBN 978-012-088479-7, pp. 451-482.

[7] J. N. Chiasson, L. M. Tolbert, K. J. McKenzie, Z. Du, “A complete solution to the harmonic elimination problem” IEEE Trans. on Power Electronics, vol.19, no.2, pp. 491-499, 2004.

[8] J. Wang, R. Wei, Q. Ge, Y. Li, “The harmonic selection elimination of multilevel converters" IEEE International Conference on Electrical Machines and Systems, 2003, vol.1, pp. 419-422.

[9] E. Y. Guan, et. al. "Fundamental modulation: Multi-pattern scheme with an entire range of modulation indices for multilevel cascaded converters" IEEE Industrial Electronics and Application Conference, 2006, 6 pages.

[10] Z. Pan, F. Z. Peng, et.al., "Voltage balancing control of diode-clamped multilevel rectifier/inverter systems" IEEE Trans. on Industry Applications, vol. 41, no. 6, 2005, pp. 1698 - 1706.

[11] J. Chiasson, L. M. Tolbert, K. J. McKenzie, Z. Du, “Control of a multilevel converter using resultant theory, IEEE Trans. on Control Systems Technology, vol.11, no.3, 2003, pp. 345-354.

[12] Z. Du, L. M. Tolbert, J. N. Chiasson, “Active harmonic elimination for multilevel converters” IEEE Trans. on Power Electronics, vol. 21, no. 2, pp. 459-469, 2006.

[13] Powersim Inc, PSIM User's Guide Version 6, Powersim Inc, 2003, http://www.powersimtech.com.

[14] Opal-RT technology Inc, RT-LAB User's manual, Opal-RT technology Inc, Version 6, 2001, http://www. opal-rt.com.

[15] J. S. Lai, F. Z. Peng, "Multilevel converters-A new breed of power converters, IEEE Trans. on Industry Applications, vol. 32, no.3, pp. 509517, 1996.

[16] L. M. Tolbert, F. Z. Peng, T. G. Habetler, "Multilevel converters for large electric drives," IEEE Trans. on Industry Applications, vol. 35, no. 1, pp. 36-44, Jan./Feb. 1999. 